\title{
THE EFFECT OF PROCESS PARAMETERS ON RESULT QUALITY OF CUT DURING LASER CUTTING OF MATERIAL
}

\author{
GREPL, M[artin]; PETRU, J[ana]; CEP, R[obert]; PETRKOVSKA, L[enka] \& ZLAMAL, T[omas]
}

\begin{abstract}
Article is focused on the area of leaser cutting of material and effects of processing parameters on the resulting quality of the cut. The laser machining process itself is influenced by many factors that can have negative effects on the resulting quality of the cut. This experimental work is done due to the needs of the aircraft industry, in which production of parts is a subject of some of the most stringent manufacturing tolerances. Therefore several influences that concurrently affect the process need to be taken into account. After the experimental work the resulting effects on the INCONEL nickel alloy machined using a CO2 gas laser are investigated using metallographic methods. The experimental part deals with the effects of laser machining processing parameters to the cut quality. The cut quality is evaluated according to partial criteria, among which are: Roughness, shape and width of the cut, an area influenced by temperature, and sticking slag (burr). A goal of this experiment was limiting of the burr occurrence at the bottom edge of the cut, and minimal heat effects on the basic material. The material for laser cutting was the INCONEL 625 alloy that is used for applications in the aircraft industry.

Keywords: Laser; Cutting; Alloy; Cut Quality
\end{abstract}

\section{INTRODUCTION}

It is widely held that the method of laser cutting has been an essential aspect of component production in the aerospace industry for a long time. However, the results of this technique are often hard to predict because there are a number of factors to consider during the actual process of laser cutting, especially in the case super alloys.

Therefore, the aim of this paper is to shed light on the parametres of laser cutting with respect to the eventual quality of the products. Consequently, a number of experiments carried out to determine the impact of process parametres on the quality of the cutting will provide a useful insight into the issue.

In order to achieve this goal, a single alloy has been chosen to assess the influence of the laser beam on this particular alloy in the cutting process. Eventually, samples of the alloy sheet cut by the $\mathrm{CO} 2$ laser were evaluated in a metallographic laboratory to reach a satisfying conclusion.

\subsection{Laser technology}

Lasers have found wide application in scientific work in astronomy and in optics, in the investigation of material characteristics and other basic research areas. Other practical applications include optical equipment for eye surgery, use in geodesy and seismography, in welding miniature parts from hard-to-melt materials, in chemistry and metallography during spectral microanalyses, etc.

Laser cutting can be:

- Sublimating - the material is removed primarily by evaporation due to the high intensity of the laser radiation in the cut area;

- Melting - the material is melted by a laser beam in the cut area and blown away by an auxiliary gas. Mainly metallic materials are cut using this process;

- Burning - a laser beam heats the material to its ignition temperature, so it can then burn in an exothermic reaction with the reactive gas (e.g., oxygen), and the slag is removed from the cutting area by an auxiliary gas. Titanium, low carbon and corrosion resistant steels can be cut this way.

Laser cutting, the most established laser material processing technology, is a method for shaping and separating a workpiece into segments of desired geometry. The cutting process is executed by moving a focused laser beam along the surface of the workpiece at a constant distance, thereby generating a narrow cut kerf. This kerf fully penetrates the material along the desired cut contour. The absorbed energy heats and transforms the prospective kerf volume into a state (molten, vaporized, or chemically changed) which is volatile or which can be removed easily. Normally, removal of the material is supported by a gas jet that, impinges coaxially to the laser beam. This cutting gas accelerates the transformed material and ejects it from the kerf. This process is successful only if the melt zone completely penetrates the workpiece. Laser metal cutting is therfore generally restricted to thin sections. While cutting has been reported through $100 \mathrm{~mm}$ sections of steel, the process is more typically used on metal sheets $6 \mathrm{~mm}$ or less in thickness.

\subsection{The laser system and the $\mathrm{CO}_{2}$ source}

The WINBRO DELTA laser system was used for this experimental work. This system allows configuration to four different types of laser sources in such way that the settings correspond to a given laser technology. Its robust construction ensures needed stability for accurate operation even during machining of complicated parts with diameters up to $1900 \mathrm{~mm}$, height $500 \mathrm{~mm}$, and weight of up to $500 \mathrm{~kg}$ [2]. 
The source Rofin DC 020 was used for cutting in continuous mode of the $\mathrm{CO} 2$ laser. The source variability allowed its usage in many applications; in the setting for laser cutting it has shown very good characteristics, primarily outstanding quality of the beam and high effectivity.

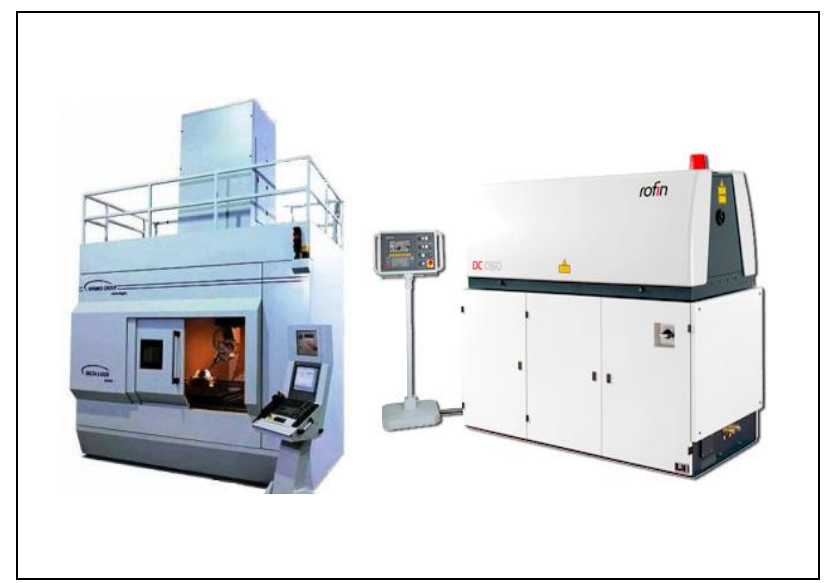

Fig. 1. The Winbro Delta laser system, the Rofin DC 020 source [2]

\subsection{The Material, Shape, and Dimensions of Test Samples}

Specific geometry of sample shapes and their dimensions were selected according to client requirements. The samples were parts, in which the finish cut quality was very important.

The provided material in the form of sheet metal has the dimensions $200 \mathrm{~mm}$ x $169 \mathrm{~mm}$. The material thickness was $1.57 \mathrm{~mm}$. The metal was processed on a bending machine before laser cutting. The processed sheet metal was fastened to a special jig on the machine table before laser cutting.

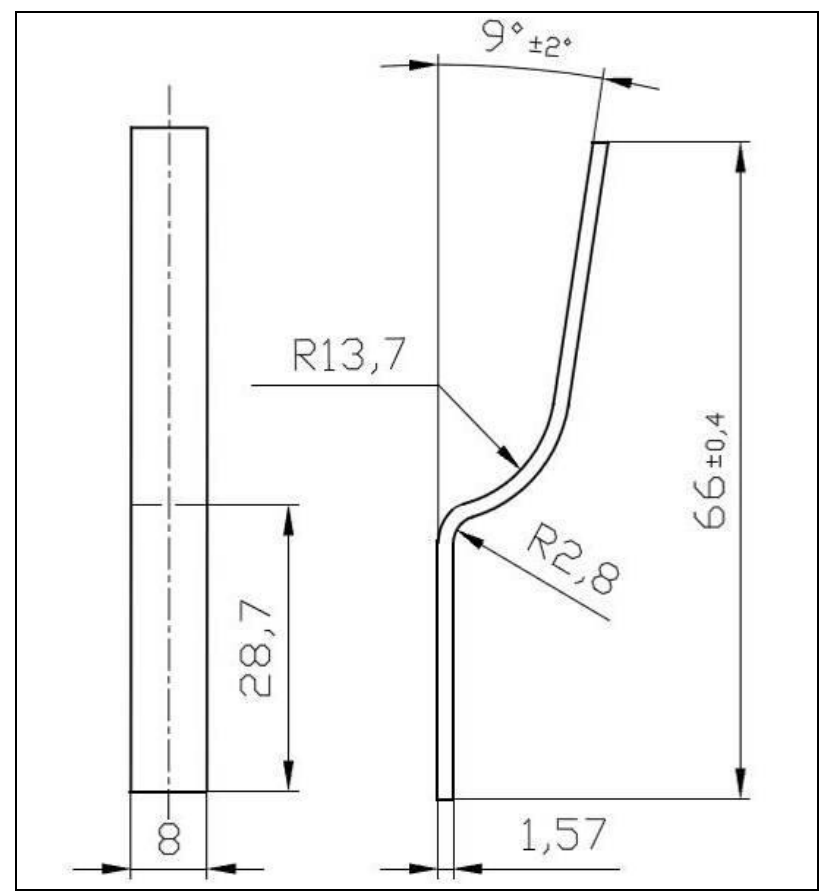

Fig. 2. The shape and dimensions of samples cut by the $\mathrm{CO} 2$ laser \begin{tabular}{|c|c|c|c|c|c|c|c|c|c|c|c|}
\hline $\begin{array}{c}\mathrm{Ni} \\
{[\%]}\end{array}$ & $\begin{array}{c}\mathrm{Cr} \\
{[\%]}\end{array}$ & $\begin{array}{c}\mathrm{Fe} \\
{[\%]}\end{array}$ & $\begin{array}{c}\mathrm{Mo} \\
{[\%]}\end{array}$ & $\begin{array}{c}\mathrm{Nb}+\mathrm{Ta} \\
{[\%]}\end{array}$ & $\begin{array}{c}\mathrm{C} \\
{[\%]}\end{array}$ & $\begin{array}{c}\mathrm{Mn} \\
{[\%]}\end{array}$ & $\begin{array}{c}\mathrm{Si} \\
{[\%]}\end{array}$ & $\begin{array}{c}\mathrm{P} \\
{[\%]}\end{array}$ & $\begin{array}{c}\mathrm{Al} \\
{[\%]}\end{array}$ & $\begin{array}{c}\mathrm{Ti} \\
{[\%]}\end{array}$ & $\begin{array}{c}\mathrm{Cb} \\
{[\%]}\end{array}$ \\
\hline 58 & 22 & 5 & 9 & 3.5 & 0.1 & 0.35 & 0.35 & 0.015 & 0.2 & 0.2 & 1 \\
\hline
\end{tabular}

Tab. 1. Chemical composition of the INCONEL 625 alloy

\subsection{Cutting of Samles Using the $\mathrm{CO}_{2}$ Laser}

Assistant gas in the form of very highly pure nitrogen stored in a pressure bottle next to the machine was used during cutting. The nozzle distance from the material surface was $3 \mathrm{~mm}$, and the position of focus was $1.5 \mathrm{~mm}$ under the material surface.

17 samples were cut in total. The parameters specified in Table 2 were used. The starting speed of laser cutting for all sets was $100 \mathrm{~mm} \cdot \mathrm{min}^{-1}$. This speed gradually increased with each sample by $100 \mathrm{~mm} \cdot \mathrm{min}^{-1}$, the final speed thus reached $1700 \mathrm{~mm} \cdot \mathrm{min}^{-1}$.

\begin{tabular}{|c|c|c|c|}
\hline \multicolumn{2}{|c|}{ Source laser parameters } & \multicolumn{2}{c|}{ Process laser parameters } \\
\hline $\begin{array}{c}\text { Source exciting } \\
\text { frequency [Hz] }\end{array}$ & 1100 & Nozzle distance [mm] & 0.9 \\
\hline Filling [\%] & 65 & Assistant gas pressure [bar] & 1.2 \\
\hline Output power [W] & 1240 & Movement speed [mm.min $\left.{ }^{-1}\right]$ & $\begin{array}{c}200 \text { to } \\
1700\end{array}$ \\
\hline
\end{tabular}
Tab. 2. The cut process parameters

The cut process parameters

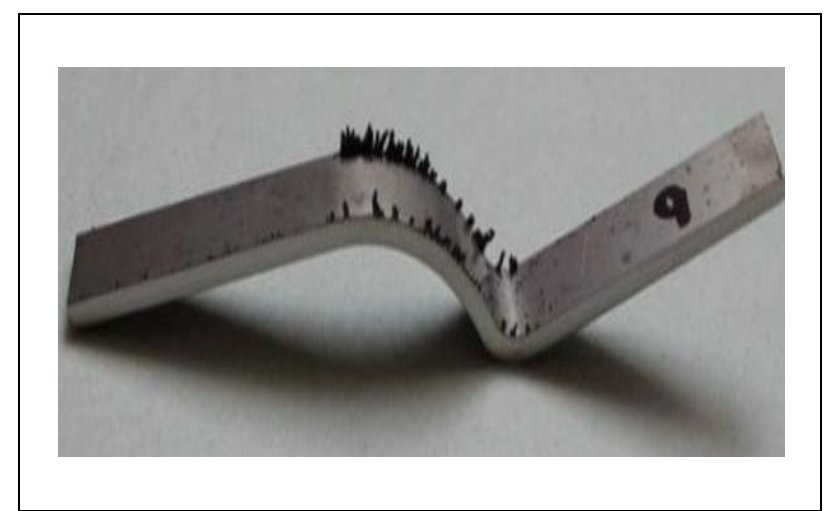

Fig. 3. The cut sample no. 9 (movement speed 900 mm.min ${ }^{-1}$ )

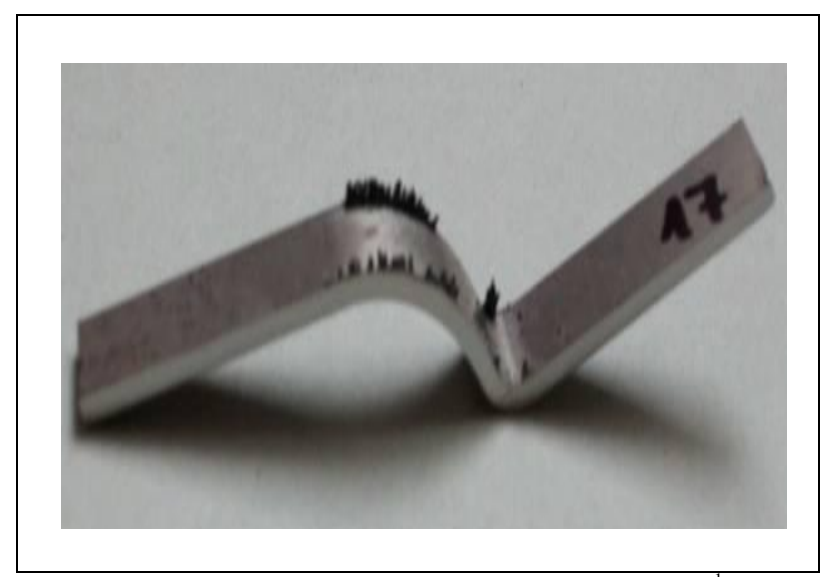

Fig. 4. The cut sample no. 17 (movement speed $1700 \mathrm{~mm} \cdot \mathrm{min}^{-1}$ )

After cutting of the samples the best cut quality was found in the sample no. 9, (Fig. 3). By setting of appropriate parameters we managed to eliminate the occurrence of burrs on the most of the samples, however, partially melted slag remained in the radius parts. 


\section{THE METALLOGRAPHIC INVESTIGA- TION AND SAMPLE EVALUATION}

Sample preparation preceded the metallographic investigation. The primary activities were sample cutting, preparation, grinding, polishing, etching, and consequent documentation using light microscopy.

After visual evaluation of the cut quality, primarily concerning the occurrence of burrs, microscopic monitoring of metallographic scratch patterns was performed. The goal was finding a possible heat effects on the material in the cut area. The heat introduced to the basic material depends among other parameters primarily on a movement speed that is why we needed to pay attention to this phenomenon.

The microscopic measurement of the TOO width was performed on selected sample sections.

2.1 The sample section of the no. 9 sample (investigated area is in the sample radius)

\begin{tabular}{|c|c|c|c|}
\hline \multicolumn{2}{|c|}{ Source laser parameters } & \multicolumn{2}{c|}{ Process laser parameters } \\
\hline $\begin{array}{c}\text { Source exciting } \\
\text { frequency [Hz] }\end{array}$ & 1100 & Nozzle distance [mm] & 0.9 \\
\hline Filling [\%] & 65 & $\begin{array}{c}\text { Assistant gas pressure } \\
{[\mathrm{bar}]}\end{array}$ & 1.2 \\
\hline Output power [W] & 1240 & $\begin{array}{c}\text { Movement speed } \\
{\left[\mathrm{mm} . \mathrm{min}^{-1}\right]}\end{array}$ & 900 \\
\hline
\end{tabular}

Tab. 3. The no. 9 sample cutting parameters

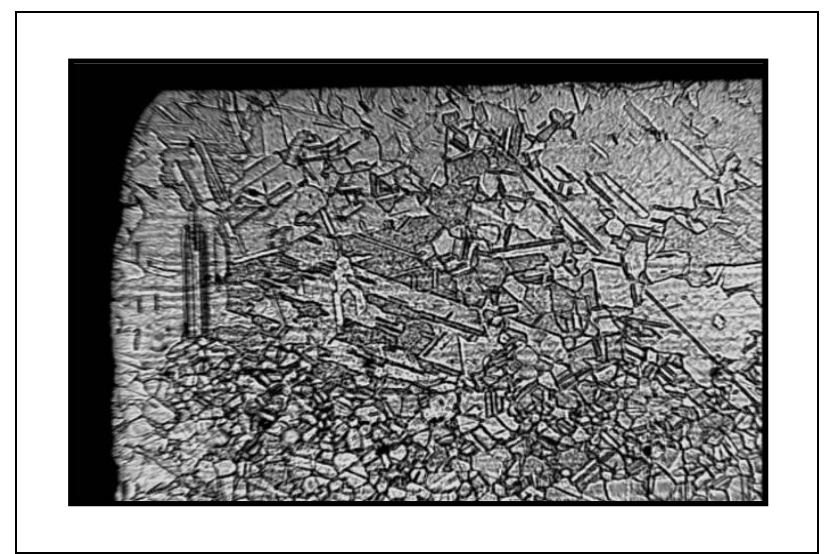

Fig. 5. The no. 9 sample microscopic structure (radius), The top part of the cut (100x magnification)

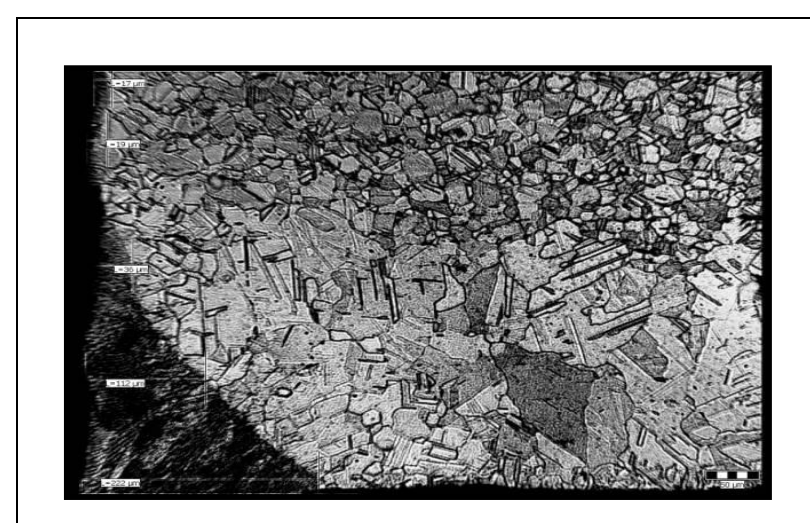

Fig. 6. The no. 9 sample microscopic structure (radius), The bottom part of the cut (100x magnification)

The top part of the cut (Fig. 5) is without apparent TOO. The beginning of the cut is slightly rounded, apparently due to taper of the laser beam. Speed increases led to the lowering of TOO height range, approximately to $1 / 3$ of the material thickness, and there was undesired widening of the width into the basic material at the same time. The reason can be the accumulation of melt in the bottom part of the cut that is a source of significant overheating that leads to the change of structure.

\begin{tabular}{|c|c|c|c|c|c|}
\hline $\begin{array}{c}\text { Measurement } \\
\text { number }\end{array}$ & 1 & 2 & 3 & 4 & 5 \\
\hline $\begin{array}{c}\text { Measured value } \\
{[\mu \mathrm{m}]}\end{array}$ & 17 & 19 & 36 & 112 & 222 \\
\hline
\end{tabular}

Tab. 4. The TOO size measured values

\begin{tabular}{|c|c|}
\hline Average value $[\mu \mathrm{m}]$ & Standard deviation $[\mu \mathrm{m}]$ \\
\hline 81.2 & 78.5 \\
\hline
\end{tabular}
Tab. 5. Statistic processing of TOO measured values

2.2 The cross-cut of the no. 9 sample (investigated area is in the sample radius)

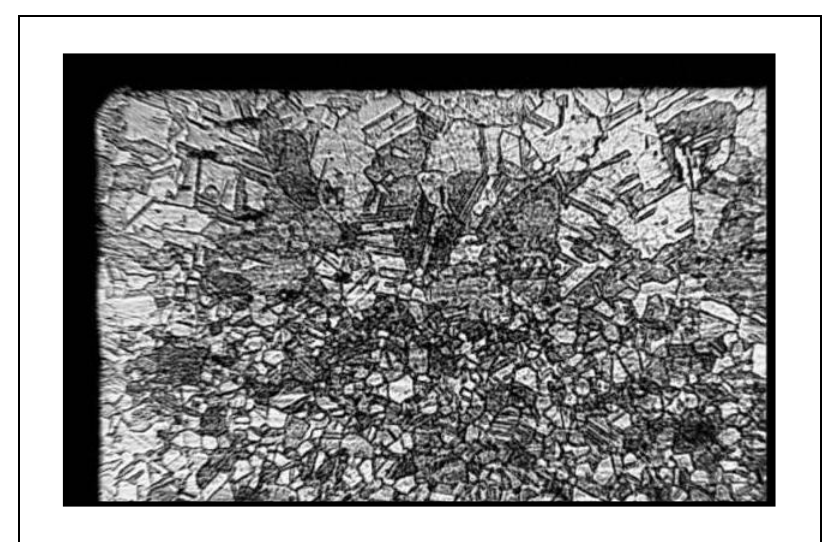

Fig. 7. The no. 9a sample microscopic structure (straight part), top part of the cut (100x magnification)

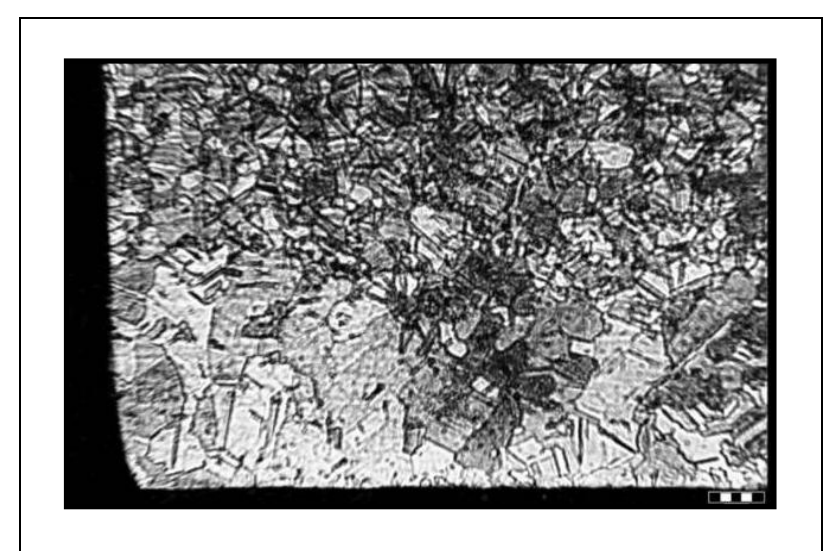

Fig. 8. The no. 9a sample microscopic structure (straight part), bottom part of the cut (100x magnification)

Both top and bottom parts are without visibly larger thicknesses of TOO. The cut quality is completely different (better) than that of the sample collected from the radius location under the same cutting conditions.

\subsection{The Achieved Results Analysis}

There were findings that led to fundamental effects on the final cut quality discovered by visual control and then by metallographic investigation. The main goal in the form of optimization of laser cut parameters in order 
to limit the occurrence of burrs at the bottom part of the cut, together with a minimum of heat influence of the basic material was performed on the sample straight parts only. The problematic place is the radius even in spite of changes of cutting parameters.

This fact forced us to focus on the sample part, where the radius is located. The originated burrs, as well as the area influenced by temperature are undesirable for functional properties of parts in extreme conditions of the aircraft industry. The cut quality depends on elimination of the above mentioned phenomena that can be the basic initiators of inter-crystalline fractures and other damage during loads in challenging conditions of the aircraft industry. Other operations of mechanical processing (grinding, machining, etc.) must be introduced to eliminate burrs and TOO after cutting by laser. These facts influence further production process, extend production times, and thus influence production economy.

\section{THE MICROSCOPIC HARDNESS MEASUREMENT}

This measurement was performed based on finding of material property changes due to temperature effects. Due to the assumption that most of the samples will have the same or very similar microscopic structure of the temperature affected area, the microscopic hardness according to Vickers was measured in one sample only. A penetrating body was pressed into the tested material under the load off $100 \mathrm{~g}$ for the time of $13 \mathrm{~s}$. This measurement was done in four places: in the heat affected area, in the place of approx. transition from $\mathrm{TOO}$, and in the basic material.

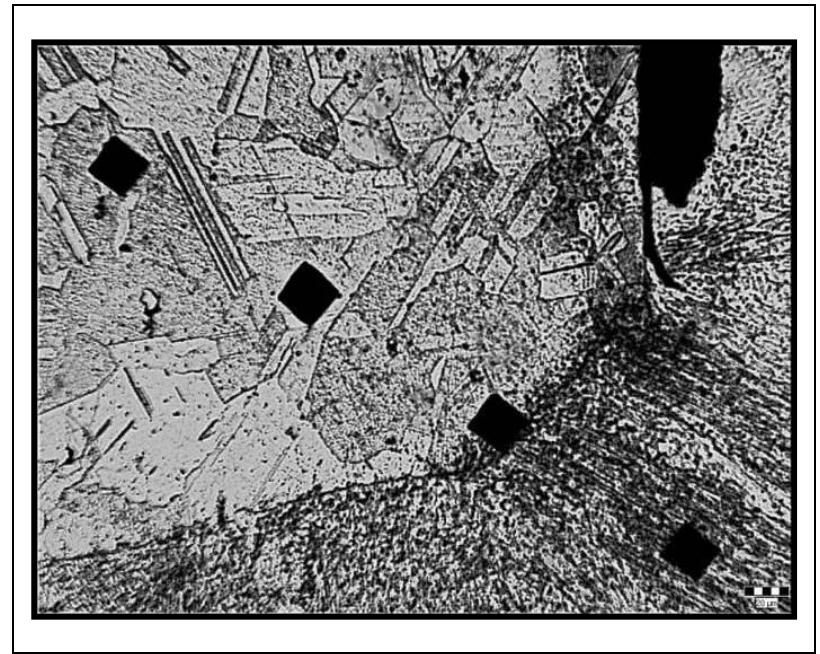

Fig. 9. The measurement of microscopic hardness of no. 9 sample (in the radius location)

From the measured results we can state that there is a significant change in hardness in comparison with the basic material due to laser cutting.

\begin{tabular}{|c|c|c|c|c|}
\hline $\begin{array}{c}\text { Measurement } \\
\text { location }\end{array}$ & TOO & $\begin{array}{c}\text { Transition } \\
\text { area }\end{array}$ & \multicolumn{2}{|c|}{ Basic material } \\
\hline $\begin{array}{c}\text { Measured } \\
\text { value }\end{array}$ & $258 \mathrm{HV}$ & $255 \mathrm{HV}$ & $257 \mathrm{HV}$ & $260 \mathrm{HV}$ \\
0.1 & 0.1 & 0.1 & 0.1 \\
\hline
\end{tabular}

Tab. 6 . The measured val
(in the radius location)

\section{CONCLUSION}

Due to a change in laser cutting parameters there was a significant limitation of burrs at the straight part of a sample; therefore it would be useful to focus on the sample part, where changes of shape take place (radius). One of the recommendations is to focus on modification of other parameters that influence the quality of laser cutting. Specifically, increase in inert gas pressure, setting of smaller distance of the nozzle from material surface, and also decrease of movement speed in the location of transition from the straight part of a sample to the radius plane. Another recommendation can be the use of alternative touchless taking off of the surface.

Based on the data obtained, the author of this paper would like to focus on drilling of super alloys by the laser beam in the future. It is belived that such a research presents a considerable challenge because it is much more complex and would consequently contribute a great deal to the efficiency of the aerospace industry.

\section{REFERENCES}

[1] DOSTAL, J. "The Effect of Process Parameters on Resulting Quality of Cut During Laser Cutting of Material." MA thesis. VŠB-Technical University of Ostrava, 2012. PRINT

[2] "Delta Laser Machining System." Winbro Group Technologies $\begin{array}{lllll}\text { Systems } & \text { Delta. } & 2008 . & & \end{array}$ <http://www.winbrogroup.com/systems/delta/>

[3] READY, J. F. LIA Handbook of Laser Materials Processing. Orlando: Magnolia Publishing, Inc., 2001. PRINT 